\title{
An E-Conversation with Prof. Roland Clift
}

\author{
Subhas K. Sikdar
}

Published online: 31 December 2013

(C) Springer-Verlag Berlin Heidelberg (outside the USA) 2013

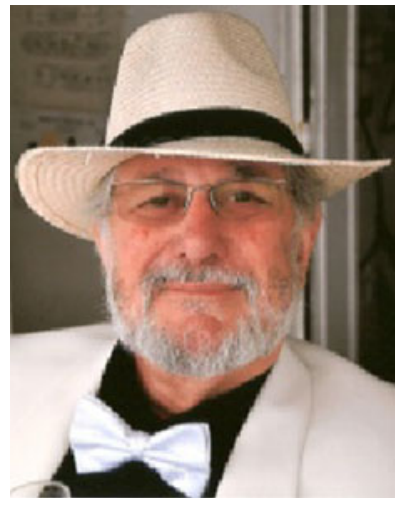

\section{Professor Roland Clift CBE FREng}

Emeritus Professor of Environmental Technology and founding Director of the Centre for Environmental Strategy at the University of Surrey; Executive Director and past President of the International Society for Industrial Ecology; past member of the Royal Commission on Environmental Pollution, the UK Ecolabelling Board and the Science Advisory Council of the Department of the Environment Food and Rural Affairs.

Prof. Roland Clift was one of the first engineering academics to initiate research on sustainability. Over the years he published numerous articles in peerreviewed journals and established himself as one of the dominant thinkers on sustainability in science and engineering fields. His influence on the need to think of engineering problems from sustainability

S. K. Sikdar $(\bowtie)$

National Risk Management Research Laboratory US Environmental Protection Agency, Cincinnati, OH, USA e-mail: sikdar.subhas@epa.gov viewpoints has been felt not just in academia but also in industry and Government all over the world. Though he is retired from his normal academic job, he is still very active in thinking of new ideas as they apply to industrial sustainability. The CTEP Editorin Chief conducted this first E-Conversation for this journal with Prof. Clift to familiarize those yet uninitiated with his thoughts and deeds.

(SKS): Roland, in a column called Forum on Sustainability, published in the May 2000 issue of this journal's predecessor publication, Clean Products and Processes, you as one of several prominent technical contributors, wrote: "Sustainability is a blissful state of existence, in which humanity's techno-economic skills are deployed, within the long-term ecological constraints imposed by the planet to provide resources and absorb emissions, to provide the welfare on which human society relies for an acceptable quality of life." After more than a decade of advancement on technical awareness of sustainability, do you have a view of sustainability now that is somewhat different from "a blissful state"? You also implied that sustainable development is the process to the goal of sustainability. What are we to make of the process when the goal cannot be realistically described?

(RC): I don't think I accept your premise. While it may be difficult to describe or define "sustainability", it is easy to see when our way of life is unsustainable and that is even more clearly the case now than it was in 2000. Rockström et al. have helped by putting numbers on where and how far we have exceeded the limits of the planet, in a way which is much more helpful than aggregated indices like the "ecological footprint". The increasing (and justified) concerns over resource scarcity-rare earths, water, land, etc.-lead to the same conclusion: that we are already 
living beyond planetary limits. This in turn reinforces the distributional dimension of sustainability - the emphasis on inter- and intra-generational equity-so the process of sustainable development is every bit as essential as it was 13 years ago. These conclusions also confirm what many people were saying in 2000: technological developments alone will not be enough to get us on a path to a sustainable society. As I sometimes say to my students, "The laws of thermodynamics are carved into stone but the laws of economics are written on paper". Given that there is nothing we can do about thermodynamics, we have to get serious about rethinking the economic system that is driving us deeper into the mire: we need systemic change which involves shifts in the economic system and in behavior. I am encouraged by the work of people like Layard and Wilkinson, and my colleague Tim Jackson, with the conclusion that, above a surprisingly low per capita GDP, quality of life is not related to consumption. I realize that their work is not widely known in North America (and unpopular where it is known) but the empirical grounding for this body of work seems strong to me-it's not just that I find it morally appealing. One of the corollaries is that we need to pay much more attention to the quality of capital stock-interpreted in a broad sense, in terms of the four- or five-capitals models-and be less obsessed by the flows that are measured by GDP. This conclusion does not leave engineers and engineering on the sidelines but it does help to redefine what our role should be.

(SKS): Yes, it makes sense that while we may not be able to define the state of sustainability, it is much easier to observe unsustainability. Time dimension of sustainability often comes up. You are stating by citing the references that in some resource areas, we are already beyond the limits set by the planet. Engineering, following its tradition will continually improve resource efficiency and find substitutes. You are implying, however, that won't be enough because the distributional dimension of sustainable development will drive sustainability innovations. (1) How will this distribution materialize in the face of private and national ownerships? And what agency do we have that can encourage and enforce this drive? (2) A second question arises from your views: granted that quality of life is independent of per capita GDP beyond a point, but what evidence do we see that where such a quality of life exists, consumption is tamed at that lower level, if people are free to choose?

(RC): You have put your finger on one of the most serious problems in achieving a global state which is anywhere near sustainable. Technology may possibly help to reduce inequality if the more technologically developed societies really promote access to more efficient processes and products. However, in the constrained world that we are moving into, access to resources will still be determined by economic and political power. I can't see a serious prospect of an international agency having the will or power to promote equity; in fact, it often seems to me that the World Trade Organization pushes in exactly the opposite direction. This is why I have increasingly tended to work with companies, particularly multi-national business-to-consumer companies: because they are the agencies that really control supply chains. The influence of individual consumers seems to me to be much less direct: put simply, they decide where to shop so, increasingly, retailers have to compete on reputation to get customers to visit the store or the website. However, I don't see much evidence that, once consumers are there, they pay much detailed attention to the credentials of individual purchases.

But the relationship_or, rather, lack of it-between GDP and quality of life can be exploited by spending on quality rather than quantity, which is what I advocate for sustainable consumption: luxury purchases rather than cheap or frugal because they have the lowest environmental impact per dollar or pound spent and can also have the greatest economic and social benefits along the supply chain. It's interesting, maybe even encouraging, that this idea is starting to be picked up, most obviously in clothing. The horrific evidence which has come out in the last year about conditions in "sweat shops" is at last making people question whether to buy cheap throw-away clothes. Sustainable Consumption means buying expensive items produced by a skilled labor force which is treated with respect. Provided that these clothes are in use for longer, expenditure on clothing need not go up but the use of resources other than labor goes down. Some companies, like Marks and Spencer in the UK, have actually started to work with charities to ensure that once you are tired of a garment you can have it reconditioned for someone else to wear. It is brave for a company to promote a scheme to reduce demand for new goods, but it's the way we have to go in "The Performance Economy".

(SKS): Sustainability is generally argued at the global scale, but the practitioners of science and engineering who want to do something to advance the cause of sustainability have to deal with problems under their control. How, in your view, do they down-scale this idea for local implementation, yet support the overall idea of sustainability?

(RC): I'm not sure it's necessary to scale down your aspirations in the geographical sense, but of course you have to be realistic and ask how you can focus your efforts (and best deploy the scarcest personal commodity in the "Northern" world: your own time) to have the greatest effect in advancing the cause of sustainability. I find that one of the benefits of the life cycle "whole system" approach is that it helps you to see beyond the purely local impacts of what you do-not just in a professional sense. 
My response to your previous question argues that even consumer purchasing can help to promote sustainability. I am encouraged by the increasing acceptance of the view that supply chains are more than series of activities that deliver goods and services, but are really systems that can cause benefits to flow in both directions. This leads to the different, and more acceptable, understanding of "sustainable consumption" which emphasizes quality rather than frugality.

(SKS): I think by "whole system" life cycle approach you are promoting the aphorism: think globally, act locally. Consumer choices leading to sustainable consumption can be influenced if the proposed consumption products appeal to the consumers, and they make economic sense. What are you thinking now in terms of what the engineering communities can do to promote sustainable consumption, and how their voices will reach the consumers?

(RC): For engineering and engineers, I hope we can be less narrowly technological; part of my hope is that engineers will see and involve themselves much more as social agents than they do now. I have written a bit on the role of the technical expert in public decisions and politics; I call my model "The Honest Broker", someone whose role is not to force a particular outcome but to ensure that all relevant information is considered and understood in reaching a decision. This kind of public role is spurned by a lot of those who currently practice engineering but I think it is a big part of the answer to those who complain that engineers do not get enough respect and that the voice of the engineering profession is too often ignored. I think it also makes the profession much more interesting; if we could announce clearly that engineers are not just technicians, it could go some way toward attracting larger numbers of really able and versatile recruits.

(SKS): You had said a number of times in conference speeches that you have not been practicing standard chemical engineering, yet we know now that chemical engineering profession has been stimulated by your work. What motivated you to start working on environmental issues at a time when chemical engineering as a profession was not involved in the teaching or research of environmental problems, and when sustainability as a motive force for research in the sciences and engineering was virtually unknown?

(RC): I can answer this one very precisely. In the late 1980s, I chaired and helped to set up the UK's national program on Clean Technology-which roughly paralleled the Pollution Prevention program in the US. By about 1991, I was getting increasingly frustrated with Clean Technology because it seemed to me that the real problem was not lack of technology but lack of understanding in how to use our technological abilities. I went to an Engineering Foundation conference in January 1991 where I met a number of people who introduced me to different ways of looking at things; they included Tim Jackson who is now a colleague in the Centre for Environmental Strategy (CES) and Walter Stahel (of the Product Life Institute in Geneva) who is a Visiting Professor here. That was when I decided to set up CES as a center to enable engineers and social scientists to work together properly. I did have people saying quite openly that I had given up chemical engineering and one of my former students, now Dean at Surrey and therefore my boss, said recently-he was introducing me at a public lecture-that he thought at the time I had gone a bit mad. I suppose it was a bit of a jump and also a bit of a risk, not so much for me as for the younger people who joined me in CES, but I think it worked out. As well as being influential, CES has been fun-and also much more interesting intellectually than particle technology which is what I had been doing! You know you are doing interdisciplinary research when you find you are working on problems that you can't even articulate within a single discipline.

(SKS): In November 2013 at a small gathering at the American Institute of Chemical Engineering annual meeting in San Francisco, a professor from MIT commented that you, in your Danckwerts memorial lecture in the US several years ago, gave so many ideas that several generations of chemical engineering research can remain busy working on them. Early in this conversation, you have mentioned about the inspiration you get from state-of-theart socioeconomic research. What impacts do you think these ideas will have on engineering research in the future?

(RC): Well. I do think Industrial Ecology (IE) has to be the lens through which we look at human society and economy and that the basic approach of Chemical Engineering has to be an integral part of IE so I hope these ideas are picked up. I sometimes sum up this aspect of IE as "Chemical Engineering outside the pipe", which was the title of my Danckwerts Lecture: chemical engineering is concerned with managing flows and stocks of materials and energy inside pipes whereas a lot of industrial ecology is about doing exactly that in the economy.

I also hope that the idea of working with the social sciences can be more accepted. I still find a lot of engineers deeply averse to engaging with social science, but I think that a narrow disciplinary approach does no one any good-actually economics is the worst example of an introverted or autopoietic discipline, and that is the main reason why neo-classical economics in particular has parted company from reality. I have found it both easy and productive to work with the kind of practical social scientist who recognizes the primacy of empirical evidence (although their evidence may be qualitative and that may require a bit of adjustment)—but even I don't have a lot of interest in grand social theory or post-modern sophistry. 
(SKS): Lastly, at this point in your life, please talk a bit about the satisfaction you have had from your teaching and research. Of the many awards, honors, and felicitation you have received, which ones do you cherish most and why?

(RC): I hope this doesn't sound too sanctimonious but, as an academic and teacher, my most important activity has been helping younger people to develop their ideas and abilities-and, of course, this sits well with the central principle of inter-generational equity. As Cicely Herbert put it, "We plant trees for those born later". I regard my students, mainly my graduate students, as my justification for having existed; when I look at where my students are now and what they are doing - that is worth more than any number of medals or certificates. One of the great privileges of being a professor is that you get to work with a string of younger people who are usually intelligent, able, motivated, and personable. I have found the relationship with doctoral students particularly worthwhile. As well as conventional $\mathrm{PhD}$ students, we set up at Surrey an industrial doctorate program. It is sufficiently different from a $\mathrm{PhD}$ that it leads to a different degree: Doctor of Engineering, EngD for short. Our EngD graduates tend to go into industrial jobs rather than academia. Some of my doctoral students have been truly spectacular, and I still see many of them regularly - in fact some of them have been in turn industrial supervisors on the EngD program. Thinking that I helped these people to develop and go into influential positions where they can "make a difference" is the greatest satisfaction.

The Danckwerts lecture and the Sir Frank Whittle Medal of the Royal Academy of Engineering are also significant for me because I see them as recognition by the engineering community that I haven't been wasting my time in some outer reaches of abstruse thought.

(SKS): My thought is that you have two kinds of students. Members of the first kind are those who had daily interactions with you during their studies and went on to carry the acquired knowledge and engineering attitude, if I can use that word, to work life. Members of the second kind are those whom you perhaps have not met, but who read your contributions, cited your papers, and followed your footsteps to influence worlds around them. Taken together, that is your legacy.

Roland, I deeply appreciate your agreeing to this conversation. I thank you much for your cooperation. 